\title{
Regular menses at 73? A peculiar presentation of postmenopausal bleeding
}

\author{
Matthew McKnoulty ${ }^{1}$, S. Scott ${ }^{2}$ \\ ${ }^{1} \mathrm{O}$ \& G SHO, Obstetrics and Gynaecology Department, Logan Hospital, Queensland, Australia \\ ${ }^{2}$ Griffith University, Queensland, Australia \\ Email: mcknom@Hotmail.com
}

Received 20 October 2013; revised 15 November 2013; accepted 21 November 2013

Copyright (c) 2013 Matthew McKnoulty, S. Scott. This is an open access article distributed under the Creative Commons Attribution License, which permits unrestricted use, distribution, and reproduction in any medium, provided the original work is properly cited.

\begin{abstract}
Post menopausal bleeding is one of the most common conditions referred to gynaecology departments. Up to $5 \%$ of these women are found to have malignant, or pre-malignant lesions, with early detection and investigation being crucial for curative treatment. We report on the case of a 73-year-old women referred for having regular menses since 14 years of age and discuss the current investigation and management of post menopausal bleeding.
\end{abstract}

Keywords: Postmenopausal Bleeding; Endometrial Hyperplasia

\section{CASE}

A 73-year-old Gravida 5 Para 5 was referred by her GP with regular menses. The patient described no change in cycle or volume of menses since menarche at age 14. Her cycle was slightly irregular occurring every 20 to 30 days, with small volume losses for 2 to 4 days. There was an irregular amount of inter-menstural bleeding that had occurred since her 20's. There was no history of dysmenorrhoea and she was not currently sexually active. On specific questioning of peri-menopausal/menopausal symptoms, there was no history of hot flushes, vaginal atrophy or mood swings. Obstetric history included five uncomplicated vaginal deliveries. A urethral sling was inserted at 63 years of age for stress incontinence. Papsmear history was unfortunately not obtained and the patient denied any history of exogenous hormonal intake. Medical history included mild hypertension requiring perindopril and unmedicated depression.

Pelvic ultrasonography revealed a 14-mm thickened irregular endometrium. Cervix and ovaries were normal. Hormonal studies found an FSH level 29 U/L, oestradiol $140 \mathrm{pmol} / \mathrm{L}$ and progesterone $<1 \mathrm{nmol} / \mathrm{L}$. These hormo- nal results were inconclusive, with FSH and Oestradiol falling outside post-menopausal range. Additionally, thyroid function was normal.

Following review in our gynaecology clinic, the patient underwent a diagnostic hysteroscopy with dilatation and curettage for post menopausal bleeding and a thickened endometrium. Hysteroscopy revealed a thickened endometrium and endometrial polyp. Histology of curetings revealed simple endometrial hyperplasia without atypia. The patient was offered a hysterectomy but has since returned to her home country of South Africa for further management.

\section{DISCUSSION}

Post menopausal bleeding (PMB) accounts for approximatly $5 \%$ of conditions referred to hospital gynaecology departments [1]. Menopause is generally defined as the cessation of menstrual bleeding for $>12$ months in women with an intact uterus. In Australia, the medial age for menopause is 51 years (95\% CI, 50 - 51) [2], with the oldest non-IVF pregnancy occurring in a 59-year-old women [3]. There were no reports of natural menopause occurring later than 65 years of age available in the literature.

As a rule, endometrial cancer or hyperplasia should be assumed to be the cause of PMB until proven otherwise, as it affects up to $10 \%$ of the female population [4]. Timely investigation of post menopausal bleeding relies on a sufficient public knowledge to appreciate the irregularity, and a diligent general practitioner or family doctor to ask about symptoms. These patients should be referred to a specialist gynaecologist for review within 2 weeks [5].

Screening for endometrial cancer in asymptomatic women has been shown to increase unnecessary operations, increase morbidity and cost with no prognostic benefit [6]. Risk factors for developing endometrial cancer include type 2 diabetes mellitus, obesity, hyperten- 
sion and long term oestrogen-only hormone replacement therapy [5].

Vaginal atrophy is the most common cause of PMB, with intra-uterine causes including endometrial atrophy (42.1\%), polyps (43\%), fibroids (5\%) and hyperplasia/ malignancy (5\%) [6]. Further investigation is required in all cases, with trans-vaginal ultrasound assessment of endometrial thickness being the first line option. Thickness cut-off varies between hospitals, however most centres agree that normal endometrium should be $5 \mathrm{~mm}$ or less [5]. An endometrial thickness of $<5 \mathrm{~mm}$ in women with PMB was found to have a sensitivity of $98 \%$ for endometrial cancer (EC), indicating a $1 \%$ chance of these women having the disease. Another study found $100 \%$ sensitivity for EC with an endometrial thickness of $4 \mathrm{~mm}$ or less [7]. Conversely, $96 \%$ of patients with EC will have an endometrial thickness $>6 \mathrm{~mm}$ in the presence of PMB.

Intra-office uterine sampling has also increased in popularity. EC detection rates using low cost, minimally invasive Pipelle sampling have been shown to be up to 99.6\% [8], however insufficient tissue sampling is common. Diagnosis of EC has subsequently occurred in up to $6 \%$ of patients with insufficient sampling, suggesting that further investigation is required within this population [9].

In diagnosing the cause of PMB, the gold standard remains hysteroscopy, dilatation and curettage [10]. In Australia, these procedures are generally performed under a general anaesthetic or sedation as a day procedure. Hysteroscopy readily diagnoses benign causes, with curettage providing histopathologic evidence to support the findings. In certain cases, such as those with endometrial polyps, curettage can also provide the cure. Unfortunately, when it comes to pre-cancerous lesions (hyperplasia, endometrial intraepithelial neoplasia), hysteroscopy alone has not been found to significantly increase the incidence of detection [11]. In those women where a precancerous lesion is found on curettage, up to $42 \%$ will have a concurrent endometrial carcinoma found at hysterectomy [12]. This has resulted in many authors suggesting that all women in whom these lesions are found, hysterectomy should be performed.

New diagnostic modalities, including clonality assays and computerised tissue morphometry, while looking promising, are not currently practical for most clinical settings and require further research [11]. Public awareness, vigilant general practitioners and appropriate investigation and referral remain the cornerstones of early detection and management of pre-cancerous and cancerous causes of post-menopausal bleeding.

\section{LEARNING POINTS}

1) Post menopausal bleeding may present in a myriad of ways and it is important for GPs to be vigilant in screening for symptoms.

2) Endometrial abnormalities may mask the natural cessation of menses, potentially leading to significant disease progression.

3) Management of women with post menopausal bleeding includes urgent specialist referral, ultrasonography and endometrial sampling.

\section{REFERENCES}

[1] Moodley, M. and Roberts, C. (2004) Clinical pathway for the evaluation of postmenopausal bleeding with an emphasis on endometrial cancer detection. Journal of $\mathrm{Ob}$ stetrics \& Gynaecology, 24, 736-741. http://dx.doi.org/10.1080/014436104100009394

[2] Do, K., Treloar, S., Pandeya, N., Purdie, D., Green, A., Heath, A. and Martin, N. (1998) Predictive factors of age at menopause in a large Australian twin study. Human Biology, 70, 1073-1091.

[3] Guinness World Records (1997) Oldest mother to conceive naturally. Jim Pattinson Group, Vancouver.

[4] Robertson, G. (2003) Screening for endometrial cancer. Medical Journal of Australia, 178, 657-659.

[5] NICE Clinical Guidelines (2005) Referral guidelines for suspected cancer in adults and children. Clinical Governance Research and Development Unit, Department of Health Sciences, University of Leicester.

[6] Gerber, B., Krause, A., Muller, H., Reimer, T., Kulz, T., Kundt, G. and Friese, K. (2001) Ultrasonographic detection of asymptomatic endometrial carcinoma in postmenopausal patients offers no prognostic advantage over symptomatic disease discovered by uterine bleeding. European Journal of Cancer, 37, 64-71. http://dx.doi.org/10.1016/S0959-8049(00)00356-7

[7] Gull, B., Karlsson, B., Milsom, I. and Granberg, S. (2003) Can ultrasound replace dilation and curettage? A longitudinal evaluation of postmenopausal bleeding and transvaginal sonographic measurement of the endometrium as predictors of endometrial cancer. American Journal of Obstetrics \& Gynecology, 188, 401-408, http://dx.doi.org/10.1067/mob.2003.154

[8] Dikkhizen, F., Mol, B., Brolmann, H. and Heintz, A. (2000) The accuracy of endometrial sampling in the diagnosis of patients with endometrial carcinoma and hyperplasia: A meta-analysis. Cancer, 89, 1765-1772. http://dx.doi.org/10.1002/1097-0142(20001015)89:8<176 5::AID-CNCR17>3.0.CO;2-F

[9] Van Doorn, H., Opmeer, B., Burger, C., Duk, M., Kooi, G. and Mol, G. (2007) Inadequate office endometrial sample requires further evaluation in women with postmenopausal bleeding and abnormal ultrasound results. International Journal of Gynecology \& Obstetrics, 99, 100-104. http://dx.doi.org/10.1016/j.ijgo.2007.05.040

[10] Epstain, E. and Valentin, L. (2004) Managing women with post-menopausal bleeding. Best Practice \& Research Clinical Obstetrics \& Gynaecology, 18, 125-143. http://dx.doi.org/10.1016/j.bpobgyn.2003.10.001 
[11] Trimble, C., Method, M., Letao, M., Lu, K., Ioffe, O., Hampton, M., Higgins, R., Zaino, R. and Mutter, G. (2012) Management of endometrial precancers. Obstetrics and Gynaecology, 120, 1160-1175.
[12] Guido, R.S., Kanbour-Shakir, A., Rulin, M.C. and Christopherson, W.A. (1995) Pipelle endometrial sampling. Sensitivity in the detection of endometrial cancer. The Journal of Reproductive Medicine, 40, 553-555. 